\title{
A toolkit to get insights into evolutionary process in the past, presence and future
}

\author{
Małgorzata Anna Gazda ${ }^{1,2^{*}}$
}

\begin{abstract}
I reviewed a book Population Genomics that fills in the noticeable lack of a general introductory textbook to population genomics, one of the most exciting and rapidly developing branches of life sciences nowadays. Highly recommended to everybody willing to broaden knowledge about basics of genomics and get recent exciting insights into many evolutionary questions not possible to be answered before.
\end{abstract}

Keywords: Adaptation, Trait, Bioinformatics, Conservation, Domestication, Evolutionary biology, Genomics, Genotyping, Sequencing

\section{Book details}

Om. P. Rajora

Population Genomics. Concepts, Approaches and Applications

Springer Nature Switzerland AG

219 Pp. xvii + 822. H/b \$ 169.99

\section{Review article}

Population genomics is one of the most exciting and rapidly developing branches of life sciences nowadays (Luikart et al. 2003). It gives a unique opportunity to provide detailed understanding of evolutionary processes (e.g. speciation, admixture, domestication, genetic drift, extinction and many more), and advance our understanding of evolution on the molecular level (Luikart et al. 2003). The field is pretty new, dating back around 20 years, with term "population genomics" used for a first time in 1998 (Gulcher and Stefansson 1998) and many approaches and concepts are still under development but a great number of theories are already well established. The book Population Genomics fills in the noticeable lack

*Correspondence: m.gazda@cibio.up.pt

2 Departamento de Biologia, Faculdade de Ciencias, Universidade do Porto, 4169-007 Porto, Portugal

Full list of author information is available at the end of the article of a general introductory textbook. The book is rather a large volume, namely with 822 pages, but that is not unexpected taking into account the size of the field. The book presents many insights to questions in evolutionary biology which were not possible to answer without genomics while addressed some of the many challenges faced by the field. I would recommend this book to everybody with interest in genomics, to gain a necessary background and ideas about how questions on the whole genome level can be answered. Some parts of the book can be read by broader, non-specialist audience, which probably will read chapters of interest rather the whole book. I would recommend the book to undergraduate, masters, and doctorate students who want to learn the fundamentals of the field. New Principal Investigators will also want a copy for lab reference, as it provides an overview of the field, and the volume would be a good basis for a course in Population Genomics.

A structure of the book is very clear, starting with introduction of the discipline, then providing details of methodology, thirdly presenting concepts and approaches to finally illustrate applications. The part dedicated to methodology is divided into three sections: sequencing methods (Part II Methods: Genotyping and Sequencing Technologies in Population Genetics and Genomics), computational tools (Part II Methods: Computational Tools for Population Genomics) and software challenges 
(Part II Methods: Population and Evolutionary Genetic Inferences in the Whole-Genome Era: Software Challenges). In the sequencing chapter the reader will follow development of sequencing technologies from allozymes to whole genome (re)sequencing in different platforms (Part II Methods: Genotyping and Sequencing Technologies in Population Genetics and Genomics). Computational chapter will familiarize you with basis of many analysis and approaches ranging from SNP and structural variants calls, through different available software for population genetics, ending on selection scans and simulations (Part II Methods: Computational Tools for Population Genetics). Regarding concepts, my top choice of chapters are the ones dedicated to selection scan, GWAS and epigenetics. In the genomic selection chapter (Part III Concepts and Approaches: Genomic Selection) authors explain how does selection work, how to detect it, what are challenges, and finally examples of selection from many studies performed on many different organisms with example of study showing that selection for superior traits for eucalyptus can be achieved in shorter time applying data from genome scan. All what you need to know about GWAS from study design and sampling ending up on modelling and designing functional experiments is explained in chapter dedicated to GWAS (Part III Concepts and Approaches: Genome-Wide Association Studies and Heritability Estimation in thee Functional Genomics Era). Mysterious epigenetics, (DNA metylation, histon modyfications and non-coding RNAs) is demystified and authors show how it can help to understand individual plasticity, patterns of epigenetic heritability and results summarized in big tables about epigenomic variation associated with human diseases (Part III Concepts and Approaches: Population Epigenomics: Advancing Understanding of Phenotypic Plasticity, Acclimatization, Adaptation and Diseases).

Throughout the book, case studies, including the data used in the original studies, are presented. This is a strength of the book. Chapters can be read separately, although sometimes it is recommended to read previous parts to have a better understanding of presented matter. Very exciting for general interest are last three chapters showing applications of population genomics for different studies as well as current advancements of many fields. For instance in crop domestication the most intriguing insights are regarding timing, place and number of domestication events, e.g. for Asian rice there is ongoing debate about number of rice domestication ranging between one and three events (Part IV Population, Evolutionary and Ecological Genetics Applications and Inferences: Population Genomics of Crop Domestication: Current State and Perspectives). Many GWAS performed on domesticated animals revealed genotype-phenotype association for numerous interesting traits such as coat color, ear morphology in pigs or traits with high importance for food production: double muscling or milk production (Part IV Population, Evolutionary and Ecological Genetics Applications and Inferences Population Genomics of Animal Domestication and Breed Development). Dog fanciers will be interested in canine genomics, with many different issues under intensive investigation such as timing of domestication, population structure and genetic basis of traits. Importantly, the book describes how many clinically crucial phenotypes are associated with genes and mutations, which can facilitate breeding and health screening for dog breeders (Part IV Population, Evolutionary and Ecological Genetics Applications and Inferences: Population Genomics of Domestication and Breed Development in Canines in the Context of Cognitive, Social and Behavioral, and Disease Traits).

A big strength of the book is the part discussing one of the most disturbing crises in genomics, the quality and stability of the software (Mangul et al. 2019). Authors discuss the influence of some popular software packages' possible errors and their impact. It is very important to keep in mind responsibility of researcher to validate the results, and possible consequences of failing to do so. The most critical software problem is complicated, duplicated code, due to lack of code optimization, which results from lack of manpower and funding to maintain the resource. It does not necessarily mean that the software do not work as expected, but there is a strong correlation between code quality and correctness (Briand et al. 2000).

In conclusion, readers should keep their eyes open for follow-up volumes or updates, because population genomics is rapidly developing. In addition, for scholars working in different genomics fields, I would recommend reading more specialized volumes (e.g. other books about population Genomics such as Paleogenomics or Population Genomics: Microorganisms. I am also truly looking forward next volume, a more applied science discussing advances of Avian Genomics in Ecology and Evolution, which will be a good read not only for academics and students but also bird enthusiasts. Already mentioned and probably very exciting for general public is paleogenomics and our ability to extract DNA from the archeological remains and try to look at the evolutionary processes in the past in a very long time scale. Why did the mammoth got extinct, how many species of hominids existed, what was a human admixture history, how human migrated? Due to new cutting edge methods we can understand better, past, presence and possibly future. This is only the tip of the iceberg of research potential in genomics and our advancement of understanding of evolution. 


\section{Acknowledgements}

The author of this work was supported by research fellowships PD/

BD/114042/2015 in the scope of the Biodiversity, Genetics, and Evolution

(BIODIV) PhD programme at $\mathrm{ClBIO} / \mathrm{InBIO}$ and University of Porto.

\section{Authors' contributions}

The author read and approved the final manuscript.

\section{Funding}

No funding sources were used to support the writing of this book review.

\section{Availability of data and materials}

Not applicable.

\section{Competing interests}

The authors declare that they have no competing interests.

\section{Author details}

${ }^{1} \mathrm{CIBIO} / \mathrm{InBIO}$, Centro de Investigacao em Biodiversidade e Recursos Geneticos, Universidade do Porto, 4485-661 Vairao, Portugal. ${ }^{2}$ Departamento de Biologia, Faculdade de Ciencias, Universidade do Porto, 4169-007 Porto, Portugal.

Received: 5 September 2019 Accepted: 11 December 2019

Published online: 20 December 2019

\section{References}

Briand LC, Wüst J, Daly JW, Porter DV. Exploring the relationships between design measures and software quality in object-oriented systems. J Syst Softw. 2000;51(3):245-73.

Gulcher J, Stefansson K. Population genomics: laying the groundwork for genetic disease modeling and targeting. Clin Chem Lab Med. 1998;36(8):523-7.

Luikart G, England PR, Tallmon D, Jordan S, Taberlet P. The power and promise of population genomics: from genotyping to genome typing. Nat Rev Genet. 2003;4(12):981-94.

Mangul S, Martin LS, Eskin E, Blekhman R. Improving the usability and archival stability of bioinformatics software. Genome Biol. 2019;20(1):47.

\section{Publisher's Note}

Springer Nature remains neutral with regard to jurisdictional claims in published maps and institutional affiliations.
Ready to submit your research? Choose BMC and benefit from:

- fast, convenient online submission

- thorough peer review by experienced researchers in your field

- rapid publication on acceptance

- support for research data, including large and complex data types

- gold Open Access which fosters wider collaboration and increased citations

- maximum visibility for your research: over $100 \mathrm{M}$ website views per year

At BMC, research is always in progress.

Learn more biomedcentral.com/submissions 